\section{Commentary: Deserved honor, or honor among thieves?}

\author{
Paul Kurlansky, MD
}

\section{Seeking honor, or honor among thieves?}

Anyone who seeks greatness, greatness flees from him, and, conversely, anyone who flees from greatness, greatness seeks him.

\section{-Talmud Bavli, Eruvin 13b}

In 1978, a group of editors established guidelines for the format of journal articles. ${ }^{1}$ The original Uniform Requirements for Manuscripts Submitted to Biomedical Journals created by "the Vancouver Group," now the International Committee of Medical Journal Editors (ICMJE), have been expanded. The Recommendations for the Conduct, Reporting, Editing, and Publication of Scholarly Work in Medical Journals ${ }^{2}$ address broader ethical issues regarding authorship. Each of the 5 journals involved in the survey by Noruzi and colleagues ${ }^{3}$ clearly indicate their endorsement of ICMJE authorship guidelines, and most require delineation of specific author contributions.

These guidelines were intended to ensure appropriate credit for those making a substantial contribution to scientific reports, while establishing responsibility and accountability for published work. The issue may seem selfevident: Listed authors should be those who have made a meaningful contribution to the work presented. However, perhaps the issue is more complex. A mentor who has had a major impact on the enthusiasm for exploring certain topics, as well as the specific research questions and analytical approaches, may not have written or even reviewed what was submitted. Does an acknowledgment on the bottom of the last line really do justice to the monumental impact on the work product? Might "honorary" authorship be a more appropriate expression of gratitude and contribution?

\footnotetext{
From the Division of Cardiac Surgery, Columbia University, New York, NY Disclosures: Author has nothing to disclose with regard to commercial support. Received for publication Dec 18, 2019; accepted for publication Dec 18, 2019; available ahead of print Jan 8, 2020.

Address for reprints: Paul Kurlansky, MD, Black Building 210, 650 West 168th St, New York, NY 10032 (E-mail: Pk2245@cumc.columbia.edu).

J Thorac Cardiovasc Surg 2021;161:163-4

$0022-5223 / \$ 36.00$

Copyright (c) 2020 by The American Association for Thoracic Surgery

https://doi.org/10.1016/j.jtcvs.2019.12.071
}

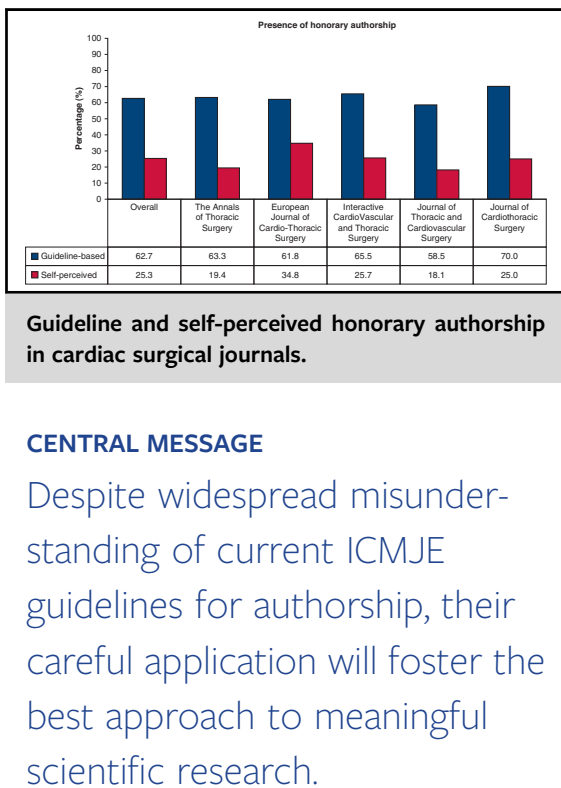

It is just in this realm of ethical uncertainty that Noruzi and colleagues' survey ${ }^{3}$ provides some very interesting, if not astounding, insights into authorship behavior in the realm of cardiothoracic surgery. Using a survey based on previous studies, they achieved a response rate $(28.9 \%)$ much lower than that in comparable studies in the medical profession. ${ }^{4,5}$ Among the authors who responded, 77.1\% claimed to be aware of ICMJE guidelines, while only $47.0 \%$ were aware of the general issue of honorary authorship—strongly suggesting that many who professed awareness of the guidelines had little knowledge or understanding of their content. Likewise, $62.7 \%$ of authors stated that at least 1 of the coauthors had performed solely nonauthorship tasks, whereas only $25.3 \%$ believed that their article contained at least 1 honorary author, once again suggesting little awareness of the meaning of honorary authorship. Clearly, the topic does not appear to be well understood, nor is its potential importance fully appreciated by our colleagues. However, beyond the potential moral outrage or professional embarrassment that might ensue, it is important to recognize that, in essence, the ICMJE recommendations not only appropriately define authorship but also, perhaps even more importantly, teach us how to best construct an article. Clinicians contributing cases to a surgical cohort may have little time or patience for article preparation; however, their clinical insight and acumen may be critical to proper focus, analysis, and conclusion. Department chairs, whose administrative, clinical, and other responsibilities afford little opportunity to 
write articles, may provide essential contributions to the direction, conduct, and conclusions of the research. In short, the guidelines are not so much a matter of policing journal authorship as they are an endorsement of the most robust methodology for creating meaningful scientific research.

\section{References}

1. Uniform requirements for manuscripts submitted to biomedical journals. International Steering Committee of Medical Editors. Br Med J. 1978;1:1334-6.
2. Defining the Role of Authors and Contributors. Available at: http://www.icmje org/recommendations/browse/roles-and-responsibilities/defining-the-role-of-auth ors-and-contributors.html. Accessed December 1, 2019.

3. Noruzi A, Takkenberg JJM, Kayapa B, Verhemel A, Dadjradj PS. Honorary authorship in cardiothoracic surgery. J Thorac Cardiovasc Surg. 2021;161: 156-62.e1.

4. Mowatt G, Shirran L, Grimshaw JM, Rennie D, Flanagin A, Yank V, et al. Prevalence of honorary and ghost authorship in Cochrane Review. JAMA. 2002;287: 2769-71.

5. Wislar JS, Flanagin A, Fontanarosa PB, Deangelis CD. Honorary and ghost authorship in high impact biomedical journals: a cross sectional survey. BMJ. 2011;343:d6128
Commentary: Honorary or incorrect

\section{Paul T. Sergeant, MD, PhD}

The article "Honorary Authorship in Cardiothoracic Surgery" by Noruzzi and colleagues ${ }^{1}$ in this issue of the Journal is an intellectual and ethically challenging work, demanding an in-depth reflection on our behavior in finalizing scientific work into a published format. The authors study the awareness and implementation of the guidelines as created by the International Committee of Medical Journal Editors (ICMJE). ${ }^{2}$

An immediate challenging observation is the word "honorary." "Honorary" stands for not needing the usual requirements. Within the publishing world, the word "ghost" authorship ${ }^{3}$ is defined as a person who has made considerable contributions to the scientific work and/or writing but is not listed as author. So as well, the absence of the presence of an author does not provide the mandatory transparency of a scientific work and the mandatory respect for those having done this work. Honorary authorships are defined less specifically, differently, or not even defined in varying scientific domains. In addition, the order of authors in a list has varied historically, with specific importance for the first and last, as well as the first 5 identified authors.

From Cardiac Surgery, Katholieke Universiteit Leuven, Leuven, Belgium.

Disclosures: Author has nothing to disclose with regard to commercial support.

Received for publication Nov 8, 2019; accepted for publication Nov 12, 2019; available ahead of print Nov 29, 2019.

Address for reprints: Paul T. Sergeant, MD, PhD, Reigersweide 16, 3390 Sint-Joris-Winge, Belgium (E-mail: Paulsergeant133@gmail.com).

J Thorac Cardiovasc Surg 2021;161:164-5

$0022-5223 / \$ 36.00$

Copyright (c) 2019 by The American Association for Thoracic Surgery

https://doi.org/10.1016/j.jtcvs.2019.11.044

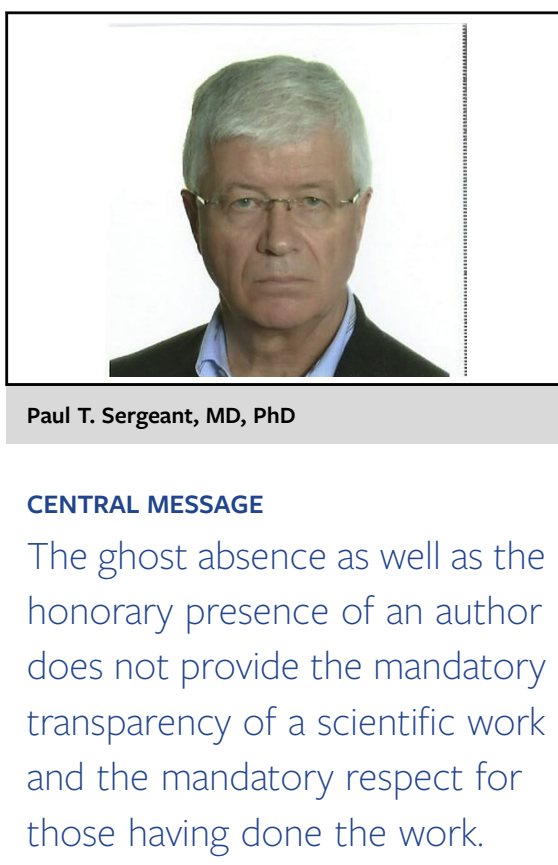

Martinson and colleagues in Nature ${ }^{4}$ (2005) classified honorary authorship under bad behavior and in the same category as falsification, fabrication, and plagiarism. However, if a mentor has influenced positively a scholar through hundreds of hours of one-to-one guidance and has impacted his or her reflection, behavior, and practice, then I do not see anything unethical in having the scholar place this mentor as an honorary author out of gratitude and respect. My mentor has always refused this gratitude and respect, even though we have worked laboriously on every letter and semicolon (in his usual manner) in several manuscripts. However, the ICMJE has defined guidelines, and guidelines are created to be followed. These guidelines were created because, indeed, the names of authors appear and disappear for unethical reasons. Let us imagine that one has designed and executed thousands of therapeutic 